\title{
The influence of different lipid environments on the structure and function of the hepatitis $C$ virus p7 ion channel protein
}

Thomas Whitfield, Andrew J. Miles, Johanna C. Scheinost, John Offer, Paul Wentworth Jr, Raymond A. Dwek, B. A. Wallace, Philip C. Biggin \& Nicole Zitzmann

To cite this article: Thomas Whitfield, Andrew J. Miles, Johanna C. Scheinost, John Offer, Paul Wentworth Jr, Raymond A. Dwek, B. A. Wallace, Philip C. Biggin \& Nicole Zitzmann (2011) The influence of different lipid environments on the structure and function of the hepatitis C virus p7 ion channel protein, Molecular Membrane Biology, 28:5, 254-264, DOI: 10.3109/09687688.2011.581253

To link to this article: https://doi.org/10.3109/09687688.2011.581253

View supplementary material ¿

曲 Published online: 23 May 2011.

Submit your article to this journal $\pi$

Џll Article views: 385

Q View related articles $₫$

Citing articles: 14 View citing articles ¿ 


\title{
The influence of different lipid environments on the structure and function of the hepatitis $\mathrm{C}$ virus $\mathbf{p} 7$ ion channel protein
}

\author{
THOMAS WHITFIELD ${ }^{1}$, ANDREW J. MILES ${ }^{2}$, JOHANNA C. SCHEINOST ${ }^{3}$, \\ JOHN OFFER ${ }^{3,4}$, PAUL WENTWORTH JR ${ }^{3}$, RAYMOND A. DWEK ${ }^{3}$, B. A. WALLACE ${ }^{2}$, \\ PHILIP C. BIGGIN ${ }^{5}$, \& NICOLE ZITZMANN ${ }^{1}$ \\ ${ }^{1}$ Oxford Glycobiology Institute, Department of Biochemistry, University of Oxford, Oxford, ${ }^{2}$ Department of \\ Crystallography, Institute of Structural and Molecular Biology, Birkbeck College, University of London, London, \\ ${ }^{3}$ The Scripps-Oxford Laboratory, Department of Biochemistry, University of Oxford, Oxford, ${ }^{4}$ National Institute for \\ Medical Research, London, and ${ }^{5}$ Structural Bioinformatics and Computational Biochemistry Unit, Department of \\ Biochemistry, University of Oxford, Oxford, UK
}

(Received 9 December 2010; and in revised form 24 March 2011)

\begin{abstract}
The hepatitis C virus (HCV) encodes the p7 protein that oligomerizes to form an ion channel. The 63 amino acid long p7 monomer is an integral membrane protein predominantly found in the endoplasmic reticulum (ER). Although it is currently unknown whether $\mathrm{p} 7$ is incorporated into secreted virions, its presence is crucial for the release of infectious virus. The molecular and biophysical mechanism employed by the p7 ion channel is largely unknown, but in vivo it is likely to be embedded in membranes undergoing changes in lipid composition. In this study we analyze the influence of the lipid environment on $\mathrm{p} 7$ ion channel structure and function using electrophysiology and synchrotron radiation circular dichroism (SRCD) spectroscopy. We incorporated chemically synthesized p7 polypeptides into artificial planar membranes of various lipid compositions. A lipid bilayer composition comprising phosphatidylcholine (PC) and phosphatidylethanolamine (PE) (4:1 PC:PE) led to burst-like patterns in the channel recordings with channel openings lasting up to $0.5 \mathrm{~s}$. The reverse ratio of PC:PE (1:4) gave rise to individual channels continuously opening for up to $8 \mathrm{~s}$. SRCD spectroscopy of p7 embedded into liposomes of corresponding lipid compositions suggests there is a structural effect of the lipid composition on the p7 protein.
\end{abstract}

Keywords: Planar lipid bilayers, ion channel, membrane proteins

Abbreviations: $\mathrm{HCV}$, hepatitis C virus; SRCD, synchrotron radiation circular dichroism; DOPC, 1,2-dioleoyl-snglycero-3-phosphocholine; POPE, 1-palmitoyl-2-oleoyl-sn-glycero-3-phosphoethanolamine; POPS, 1-palmitoyl2-oleoyl-sn-glycero-3-phospho-L-serine; LPPG, 1-palmitoyl-2-hydroxy-sn-glycero-3-[phospho-RAC-(1-glycerol)]; LPPC, 1-palmitoyl-2-hydroxy-sn-glycero-3-phosphocholine; DPC, dodecylphosphocholine; ER, endoplasmic reticulum; BLM, black lipid membrane; EM, electron microscopy; GST, glutathione-S-transferase; GT, genotype; RP-HPLC, reverse phase high performance liquid chromatography; MLV, multilamellar vesicle; SUV, small unilamellar vesicle; TFE, trifluoroethanol; TM, transmembrane; SD, standard deviation.

\section{Introduction}

$\mathrm{HCV}$ is a major cause of chronic liver disease worldwide (Di Bisceglie 1997) and constitutes a global public health problem. There is no vaccine available and the current standard of care treatment, a combination of pegylated interferon alpha and ribavirin, is effective in only about half of patients treated and causes severe sideeffects (reviewed in Feld and Hoofnagle 2005). There is an urgent need for improved antiviral therapeutics aimed at established, as well as novel, drug targets. One such target is the HCV p7 protein, which is crucial for the secretion of infectious particles (Sakai et al. 2003, Steinmann et al. 2007). However, to date little is known about the exact role of the HCV p7 ion channel within the infectious viral life cycle. The topology, location within the cell, and some functional characteristics of p7 have been reported (Carrere-Kremer et al. 2002,

Correspondence: Dr Philip C. Biggin, PhD, Structural Bioinformatics and Computational Biochemistry, Department of Biochemistry, University of Oxford, South Parks Road, Oxford OX1 3QU, UK. Tel: +44 1865 613305. Fax: +44 1865 613238. E-mail: Philip.biggin@bioch.ox.ac.uk; or, Dr Nicole Zitzmann, PhD, Oxford Glycobiology Institute, Department of Biochemistry, University of Oxford, South Parks Road, Oxford, OX1 3QU. Tel: +44 1865 275341. Fax: +44 1865275716. 
Griffin et al. 2004, Griffin et al. 2005, Haqshenas et al. 2007).

The HCV p7 monomer is a small hydrophobic protein of 63 amino acids (Lin et al. 1994). Sequence analysis of different HCV isolates indicate the existence of two hydrophobic transmembrane (TM) helices connected by a short cytoplasmic loop; a double membrane-spanning topology in the ER with the $\mathrm{N}$ and C-termini facing the ER lumen has been suggested (Carrere-Kremer et al. 2002). The possibility of an inactive L-shaped transport form of $\mathrm{p} 7$ with the $\mathrm{C}$-terminus being exposed on the cytoplasmic side has also been proposed (Griffin et al. 2005).

In vitro studies show that $\mathrm{p} 7$ monomers assemble to form cation-selective ion channels. A recent report demonstrated proton conductance of HCV p7 (Wozniak et al. 2010). Electron microscopy (EM) experiments on bacterially expressed GST- or GST-his-tagged p7 monomers suggest that they assemble as hexameric ion channels with an inner pore diameter of $2.3 \mathrm{~nm}$ (Griffin et al. 2003). GST-FLAG-p7 has been shown to assemble with heptameric stoichiometry (Clarke et al. 2006). Molecular modeling of $\mathrm{p} 7$ has previously suggested a plausible arrangement for a hexameric bundle (Patargias et al. 2006) with a predicted inner pore diameter of approximately $1.5 \mathrm{~nm}$, though higher oligomerization states were not explicitly considered. Solid state NMR experiments have concluded that the C-terminal helix adopts a tilt of $10^{\circ}$ with respect to the membrane normal and the $\mathrm{N}$-terminal helical section adopts a tilt of $25^{\circ}$ (Cook and Opella 2010). Conductances of up to $100 \mathrm{pS}$ have been reported previously for cation-selective p7 ion channels incorporated into planar lipid bilayers (Pavlovic et al. 2003). Recently we have demonstrated that the N-terminal helix is likely to form the transmembrane pore (Chew et al. 2009) and more specifically, that the position which corresponds to His 17 (in the $\mathrm{JFH}-1$ strain) lines the interior of the pore and is accessible to aqueous solution. We have since used that information in conjunction with coarse grain-molecular dynamics (CG-MD) simulations and electron microscopy to put forward the most complete model of a hexameric assembly of $\mathrm{p} 7$ to date (Luik et al. 2009).

Although most of the recent EM reports have suggested that the oligomeric arrangement (for either hexameric or heptameric states) is one comprised of helical hairpins, an L-shaped form of $\mathrm{p} 7$ has also been proposed (Griffin et al. 2005), but it remains unclear what role if any this form might have. In this work we show that different bilayer compositions give rise to very different ion channel behaviour in an artificial bilayer system. SRCD spectroscopy gives a lipiddependent signal. The results lead us to speculate on two possibilities which are not mutually exclusive: (i) That the lipid composition changes the orientation of the two helices with respect to the bilayer, and (ii) that the lipid composition could alter the preferred oligomeric state. The latter has recently been demonstrated for the Staphylococcus aureus mechanosensitive channel, MscL, where tetramers are formed in LDAO (the same detergent used in the crystal structure), but pentamers are formed in Triton X-100 and $\mathrm{C}_{8} \mathrm{E}_{5}$ detergents (Dorwart et al. 2010).

\section{Experimental}

Peptide synthesis

HCV p7 of genotype (GT) 1a, strain H77 was synthesized using standard Boc/benzyl peptide synthesis with in situ neutralization methodology (Schnolzer et al. 1992). Crude peptide was purified by semi-preparative reverse phase-HPLC (RP-HPLC) and its identity was confirmed by electrospray mass spectrometry. The purity of all peptides used in this study was $>95 \%$ as determined by analytical RP-HPLC.

\section{Lipids}

1,2-Dioleoyl-sn-glycero-3 phosphocholine (DOPC), 1-palmitoyl-2-oleoyl-sn-glycero-3-phosphoethanolamine (POPE), 1-palmitoyl-2-oleoyl-sn-glycero-3phospho-L-serine (POPS), 1-palmitoyl-2-hydroxysn-glycero-3-[phospho-RAC-(1-glycerol)] (LPPG), 1-palmitoyl-2-hydroxy-sn-glycero-3-phosphocholine (LPPC) and dodecylphosphocholine (DPC) were purchased from Avanti Polar Lipids, Alabaster, AL, US. Lyophilized lipids were dissolved in chloroform, dried under $\mathrm{N}_{2}$ gas and resuspended in $n$-decane at $25.0 \mathrm{mg} / \mathrm{ml}$.

\section{Channel recordings}

Artificial bilayer membranes comprising different lipid compositions (Supplementary Table 1, available online) were prepared. The following protocol is representative of the method used to produce bilayers of various lipid compositions. $5 \mathrm{mg}$ of a $4: 1(\mathrm{w} / \mathrm{w})$ mixture of DOPC and POPE were dissolved in $1 \mathrm{ml}$ chloroform, dried under a stream of $\mathrm{N}_{2}$ gas and re-suspended in $n$-decane at $25 \mathrm{mg} / \mathrm{ml}$. For channel recordings, a Delrin cup chamber system was used with an aperture diameter of $150 \mu \mathrm{m}$. Experiments were performed at $24 \pm 1^{\circ} \mathrm{C}$. The chambers separated by the aperture were filled with $1 \mathrm{ml}$ buffer ( $300 \mathrm{mM} \mathrm{KCl}, 5 \mathrm{mM} \mathrm{K}^{+}$-HEPES, $\mathrm{pH} 7.0$ ). Formation of the bilayer and induction of channel activity was achieved using a pre-treatment protocol adapted from Mehnert et al. (2007) and includes lipid pre-treatment of the $150 \mu \mathrm{m}$ aperture prior to contact with the buffer solution. To smooth the aperture's 
irregularities, a drop of a $5 \mathrm{mg} / \mathrm{ml}$ lipid preparation was applied and dried under $\mathrm{N}_{2}$ gas. Approximately $0.6 \mu \mathrm{l}$ of the peptide stock solution in trifluoroethanol (TFE) $(80 \mu \mathrm{g} / \mathrm{ml})$ was brushed across the aperture together with approximately $0.4 \mu \mathrm{l}$ of the lipid suspension and incubated at room temperature for $5 \mathrm{~min}$. The buffer level was subsequently raised and lowered until a bilayer was formed. P7 was incorporated into the bilayer in the presence of a constant voltage (usually $-60 \mathrm{mV}$ ). In most cases, reconstitution and channel activity occurred within $2 \mathrm{~min}$ after the negative voltage was applied $(n>230)$. In control experiments where pure TFE or ethanol alone were added, no ion channel activity was observed $(n=35$, waiting time $=40 \mathrm{~min}$ ). Channel recordings were performed at constant voltage ranging from $-80 \mathrm{mV}$ to $+80 \mathrm{mV}$. When planar lipid bilayers were exposed to $\mathrm{p} 7$ (purified from independent batches of synthesis), currents were observed in more than 250 experiments performed on 38 independent experimental days.

The reversal potential of currents seen with $\mathrm{HCV}$ p7 ion channels was determined by changing the potential across the bilayer in $10 \mathrm{mV}$ steps for at least $30 \mathrm{~s}$ at each potential and plotting a mean currentvoltage graph. Cation transference numbers were calculated as described by Myers and Haydon (Myers and Haydon 1972).

\section{Data analysis}

Currents were recorded using a MultiClamp 700A system from Axon Instruments (Union City, US) and the data were filtered with a Bessel-8-pole low-passfilter at $100 \mathrm{~Hz}$. Shut events shorter than $15 \mathrm{~ms}$ were considered part of a burst and excluded from single ion channel analysis. Data were analyzed using Clampfit. Details of individual experiments are given in the corresponding figure legends.

For the calculation of the current-voltage curves of the different p7 conductance states, current histograms comprising between 3,000 and 7,600 single channel opening events were generated for each of the traces. The histograms showed three predominant conductance states, the values of which were used for analysis in I/V plots.

Events amplitude histograms were generated by pClamp (Clampfit) software from records of at least 1,500 single opening events. Histograms were fitted with three Gaussian distributions as described elsewhere (Ismailov et al. 1995, Yang et al. 1997).

\section{Proteoliposome preparation}

Lipids were suspended in a chloroform/methanol (3:1) mixture and placed into glass tubes. The solvent was evaporated under a stream of nitrogen gas until a thin lipid film was formed. Residual chloroform was removed in a vacuum centrifuge under reduced pressure. Lipid films (15 mg total lipid) were suspended in $1 \mathrm{ml}$ deionized $\mathrm{H}_{2} \mathrm{O}$ and subsequently hydrated by vortexing for $2 \mathrm{~h}$. The resulting multilamellar vesicles (MLVs) were extruded 21 times through a polycarbonate filter of $80 \mathrm{~nm}$ pore diameter using a Mini-Extruder device (Avanti Polar Lipids), which resulted in the creation of small unilamellar vesicles (SUVs). These were then purified by size exclusion chromatography using Sephadex-G50 (medium) resin (Amersham Bioscience, Piscataway, NJ, USA). An appropriate amount of 7 peptide dissolved in TFE ( $3 \mathrm{mg} / \mathrm{ml}$ ) was added to the lipid suspension to reach a lipid/peptide ratio of 100:1.

\section{SRCD measurements}

SRCD spectra were collected on beamline UV1 of the ISA synchrotron facility located at the University of Aarhus, Denmark. After each beam fill the instrument was calibrated using camphor-10-sulphonic acid (Sigma Aldrich) at $20^{\circ} \mathrm{C}$ (Miles and Wallace 2006).

P7 samples were prepared by incorporation of the peptide into SUVs as described above. The peptide/ detergent samples were prepared by dissolving $\mathrm{p} 7$ in LPPC, LPPG or DPC at a peptide concentration of $1 \mathrm{mg} / \mathrm{ml}$ and detergent concentrations of $1 \%$. All samples were prepared freshly and stored on ice in the dark until use. The final protein concentrations were determined by absorbance measurement (NanoDrop UV/VIS spectrophotometer) using the theoretical extinction coefficient of $\mathrm{p} 7\left(22460 \mathrm{M}^{-1} \mathrm{~cm}^{-1}\right.$, calculated using the ProtParam tool at http://www.expasy.org). A total of $25 \mu \mathrm{l}$ of sample were loaded into a $0.0024 \mathrm{~cm}$ path length demountable cylindrical quartz Suprasil cell (Hellma Ltd, UK), and allowed to equilibrate in the SRCD instrument at $20^{\circ} \mathrm{C}$ for $1 \mathrm{~min}$, under continuous nitrogen purge. Spectra were collected in $1 \mathrm{~nm}$ steps from $280-170 \mathrm{~nm}$ with a dwell time of $1 \mathrm{~s}$ and a spectral bandwidth of $1 \mathrm{~nm}$.

For each of the SRCD spectra, three scans of both the sample and the baseline (containing the lipid or detergent alone) were averaged and subtracted. Baseline subtracted spectra were zeroed between 260 and $270 \mathrm{~nm}$ and smoothed with a third order SavitskyGolay algorithm (Savitsky and Golay 1964) using the CDTool processing software (Lees et al. 2004). Spectra are expressed in delta epsilon units, calculated using a mean residue weight of 111.4 .

Protein secondary structure analyses were undertaken using the DichroWeb analysis web server (Whitmore and Wallace 2008) with reference dataset 7 (Sreerama and Woody 2000) and the Selcon3 
(Sreerama and Woody 1993, Sreerama et al. 1999), ContinLL (van Stokkum et al. 1990) and CDSSTR (Sreerama and Woody 2000) algorithms. The NRMSD parameter reported is from the ContinLL analyses and is a measure of the goodness-of-fit of the calculated secondary structure to the experimental data, with values of $>0.2$ being indicative of a poor fit, and suggesting that the protein or peptide contains a type of secondary structure not well-represented in the reference dataset.

\section{Results}

\section{Ion channel activity of $p 7$ in different lipid environments}

We tested the effect of a variety of different lipid compositions on bilayer formation and $\mathrm{p} 7$ ion channel activity in a black lipid membrane (BLM) set-up. These lipids comprised DOPC (PC), POPS, POPE (PE), and POPC. P7 channel activity was observed in bilayers of various lipid compositions; however, single channel openings were only observed in DOPC, DOPC:POPS:POPE (4:1:1) and most reproducibly in DOPC:POPE (1:4), and DOPC:POPE (4:1) bilayers (Supplementary Table 1, available online).

When incorporated into a lipid bilayer composed of a 4:1 ratio of $\mathrm{PC}$ and $\mathrm{PE}, \mathrm{p} 7$ forms ion channels which give rise to burst-like firing patterns, with opening states typically lasting several hundred milliseconds (maximum opening times of up to $0.5 \mathrm{~s}$ were observed) (Figure 1A, left panel). Typical recordings (Figure 1B) show two main opening states and one sub-conductance state, which appear across all voltages tested and data analysed. The mean conductance values were $28.7 \pm$ $1.4 \mathrm{pS}$ and $21.4 \pm 1.3 \mathrm{pS}$ for the two main states, respectively, and $13.0 \pm 1.4 \mathrm{pS}$ for the sub-conductance state. A representative current amplitude histogram based on the analysis of approximately 2300 individual channel opening events revealed that the subconductance state (at $10.0 \pm 6.1 \mathrm{pS}$ ) is observed more frequently than the closed state and the two main conductance states. A representative histogram recorded at $+20 \mathrm{mV}$ is shown in Figure 2A, left panel.

In contrast, when the reverse lipid ratio of PC:PE (1:4) was used to construct a PE-rich bilayer, the typical burst-like pattern of the PC-rich bilayer was replaced by less frequent channel openings which lasted as long as $8 \mathrm{~s}$ (Figure 1A, right panel). Analysis of approximately 1500 opening events led to a current amplitude histogram similar to that observed for channels in the PC-rich bilayer. In PE-rich bilayers the channel opens to two main opening states at $24.1 \pm 0.6 \mathrm{pS}$ and $17.8 \pm 1.6 \mathrm{pS}$, respectively. The sub-conductance state was detected at $10.4 \pm 0.8 \mathrm{pS}$ (Figure 2A, right panel).
Open time histograms are shown in Figure 2C. The mean opening times of $\mathrm{p} 7$ incorporated into bilayers containing 4:1 PC:PE and PC:PE (1:4) was $0.095 \pm$ $0.018 \mathrm{~s}$ (standard deviation [SD]) and $1.0 \pm 0.32 \mathrm{~s}$ (SD), respectively.

For both lipid membrane compositions the currentvoltage relationships of all p7 conductance states observed exhibited ideal ohmic behaviour throughout the voltage range tested, from $-80 \mathrm{mV}$ to $+80 \mathrm{mV}$ (Figure 2B), confirming that the ion channel and related states are not voltage-gated and that there is no difference in channel behaviour at positive or negative voltages. We observed cation selectivity of $\mathrm{p} 7$, as reported previously (Premkumar et al. 2004). Ion selectivity was determined as described (Melton et al. 2002) and was not affected by the change from PC-rich to PE-rich lipid bilayers. Currents recorded in experiments ( $n=6$ each) when the cis-chamber contained $500 \mathrm{mM} \mathrm{NaCl}$ and the trans-chamber $50 \mathrm{mM} \mathrm{NaCl}$ resulted in mean reversal potentials of $32.3 \pm 1.2 \mathrm{mV}$ (PC:PE 4:1) and $34.1 \pm$ $1.9 \mathrm{mV}$ (PC:PE 1:4), respectively.

The value of the transference numbers for cations was found to be $0.774 \pm 0.010$ (PC:PE 4:1) and $0.790 \pm 0.016$ (PC:PE 1:4), respectively, whereas the anion transference numbers were calculated at $0.226 \pm 0.010$ (PC:PE 4:1) and $0.210 \pm 0.016$ (PC:PE 1:4), respectively.

\section{SRCD analysis of $H C V p^{7}$}

SRCD spectroscopy provides a higher signal/noise ratio than conventional lab-based circular dichroism (CD) instruments and hence is able to detect small differences in the secondary structure of a peptide when conditions are changed; the higher light flux of the synchrotron enables the examination of samples with high lipid/ protein ratios, which is not possible in a conventional CD instrument; these high lipid/protein ratios limit absorption flattening artifacts associated with membrane samples (Wallace and Mao 1984).

SRCD spectroscopy experiments on the influence of detergent chain length and head group were undertaken in order to determine the peptide secondary structure in these various chemical environments. Figure 3A shows SRCD spectra of $p 7$ dissolved in either DPC, LPPC or LPPG. All three detergents produced identical SRCD spectra of $\mathrm{p} 7$. The calculated secondary structure derived from these data was $74 \% \alpha$-helical, $4 \%$ $\beta$ strand, $11 \%$ turn and $11 \%$ unordered conformation (Supplementary Table 2, available online). The goodness-of-fit parameter (NRMSD) was $\sim 0.10$, indicating a reasonable agreement between the calculated structure and the experimental data.

In order to study the structurally-related functional differences of $\mathrm{p} 7$ observed in the electrophysiology 
A

PC:PE (4:1)

PC:PE (1:4)

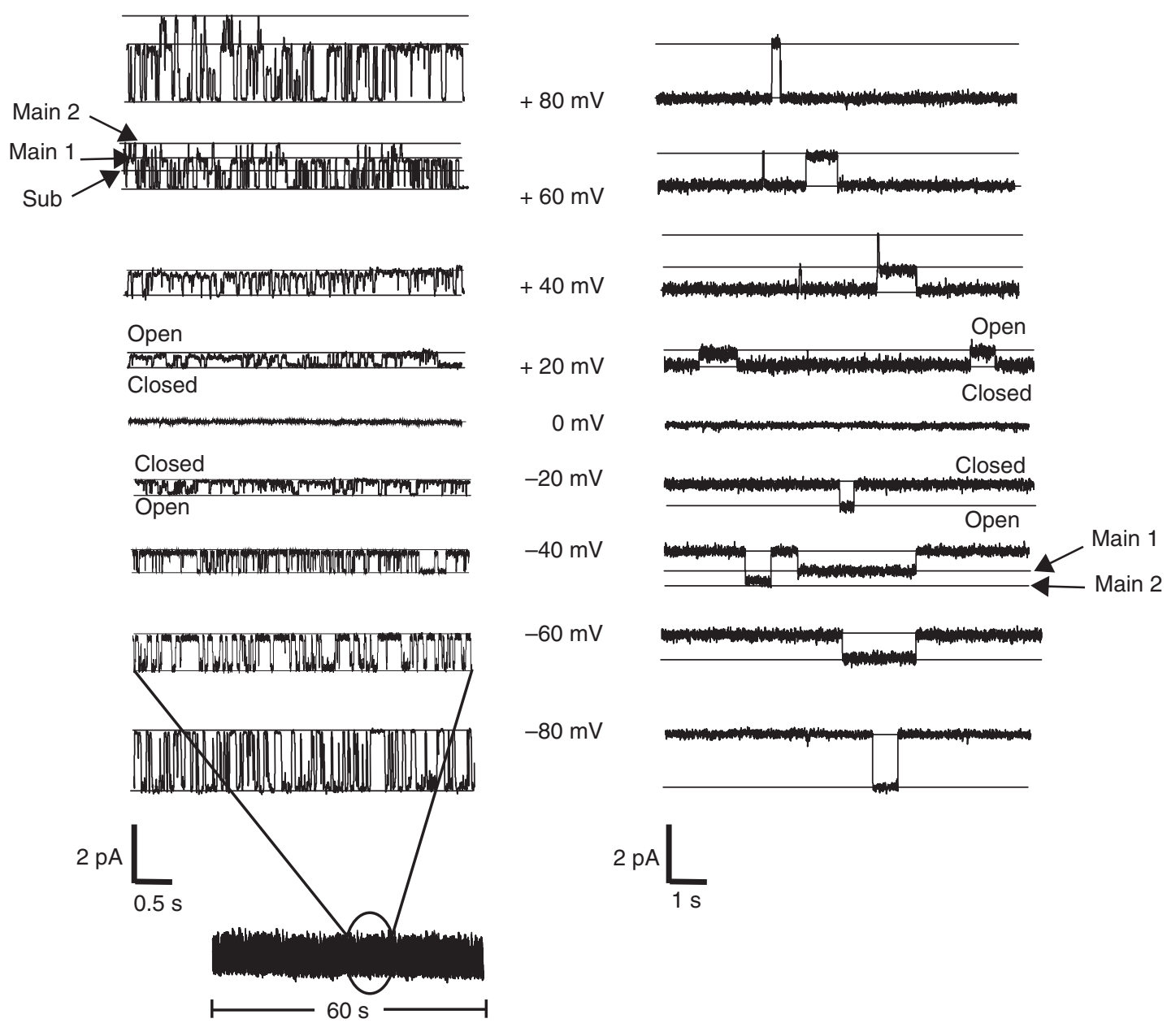

B

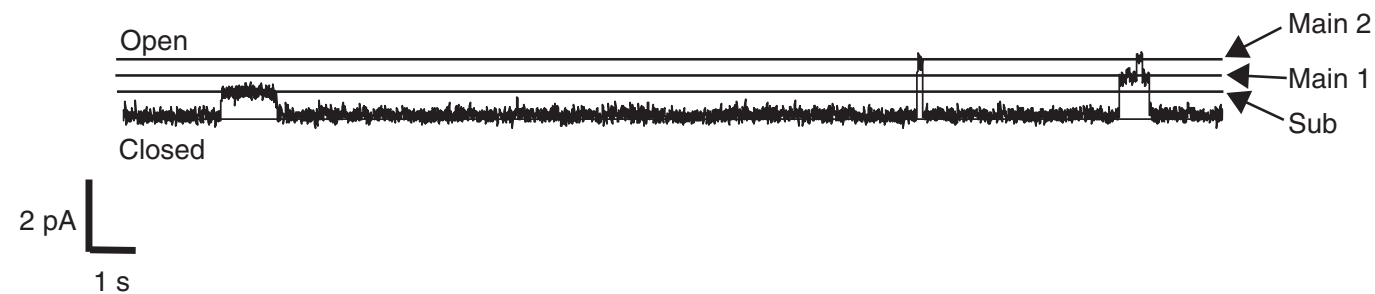

Figure 1. Ion channel recordings of $\mathrm{p} 7$ in PC-rich and PE-rich lipid environment. (A) Examples of channel recordings from $\mathrm{p} 7$ reconstituted into planar lipid bilayers of PC: PE (4:1) (left) and PC:PE (1:4) (right). Representative traces of $\mathrm{p} 7$ at different voltages reveal single channel openings of p7 $\left(300 \mathrm{mMKCl}, 5 \mathrm{mMK}^{+}\right.$-HEPES, pH=7.0). The closed and open states are indicated by the black lines. The main and sub-conductance states are indicated by the black arrows. (B) Representative trace of a PC:PE (1:4) experiment showing two main and one sub-conductance state.

experiment, the peptide was incorporated into SUVs with either a PC-rich or PE-rich lipid composition (Figure 3B). We used SUVs with high lipid-topeptide ratios to better mimic the electrophysiological conditions.

The SRCD spectra of $p 7$ incorporated into PCand PE-rich SUVs differed significantly. In PE-rich
SUVs, a predominantly $\alpha$-helical conformation (76\% $\alpha$-helix, $2 \% \beta$ strand, $11 \%$ turn and $11 \%$ unordered conformation) (Supplementary Table 2, available online) was observed, similar to that seen in detergents. However, for $\mathrm{p} 7$ in PC-rich SUVs the spectrum could not be accurately quantified (NRMSD $>>0.20$ ) as apparently none of the proteins in the reference 
A

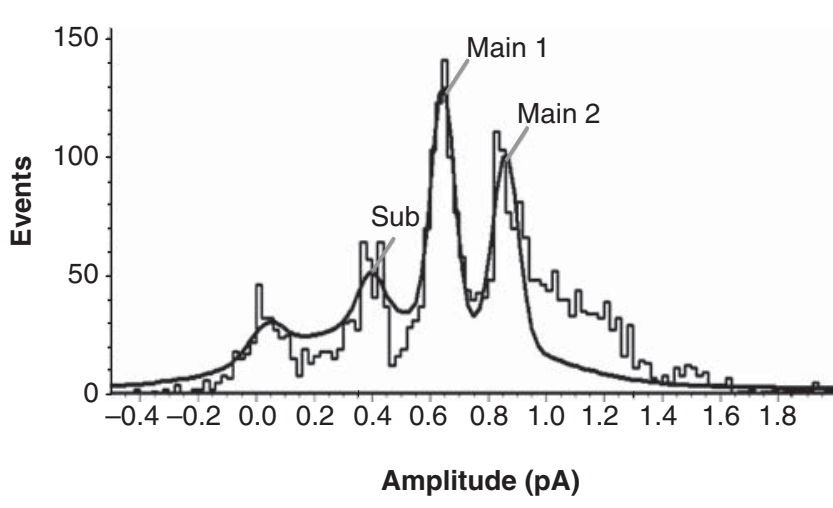

B

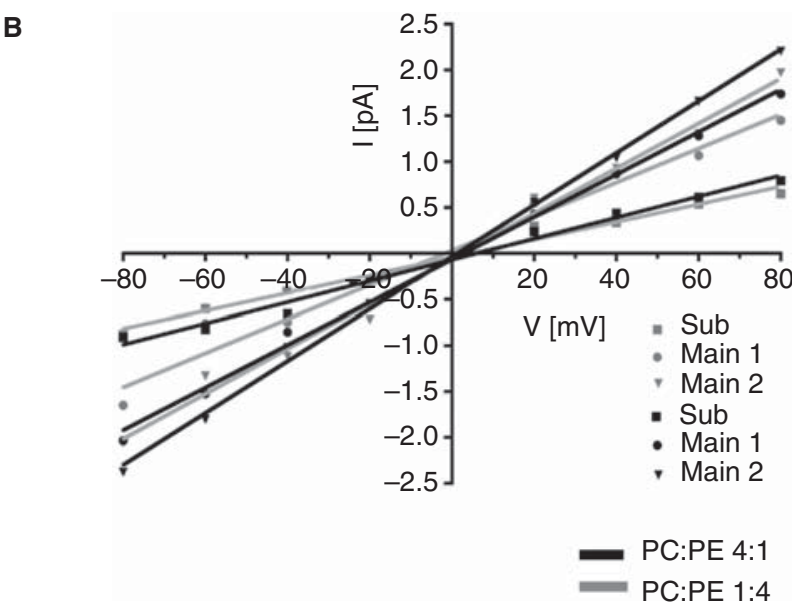

C

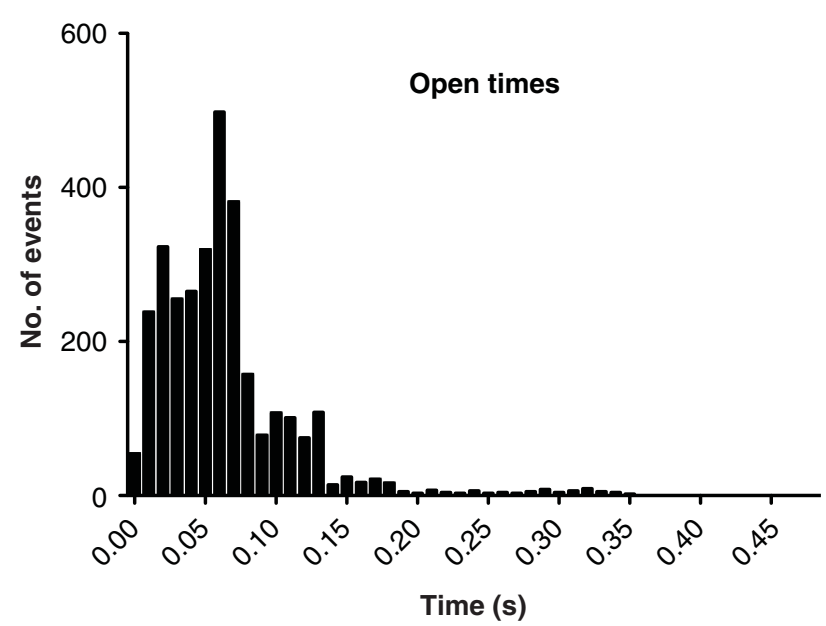

PC:PE 1:4

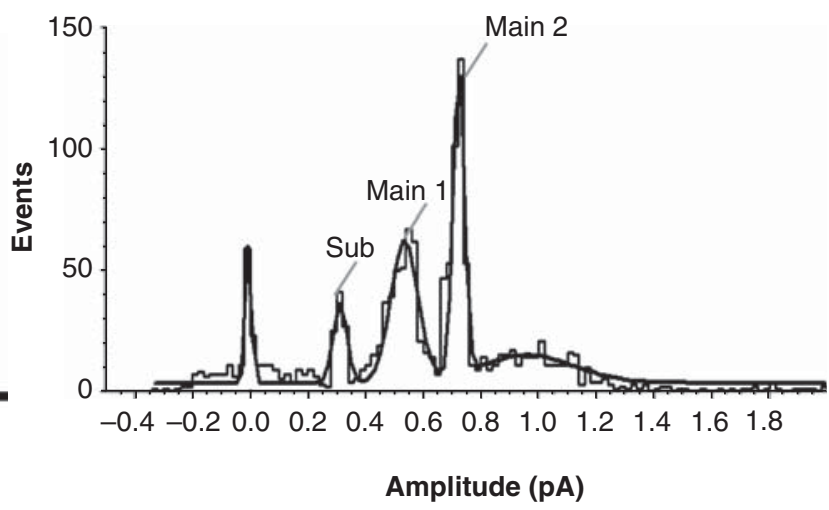

Amplitude (pA)
Figure 2. Analysis of 7 ion channel recordings in PC-rich and PE-rich lipid environment. (A) Representative current amplitude histograms of p7 reconstituted into bilayers containing PC: PE (4:1) (left panel) and PC:PE (1:4) (right panel). The traces were recorded at $+30 \mathrm{mV}$. When reconstituted into bilayers of PC:PE (4:1) the channel opens to two main open states at $28.7 \pm 1.4 \mathrm{pS}$ standard deviation (SD) and $21.4 \pm 1.3 \mathrm{pS}(\mathrm{SD})$ and one sub-conductance states at $13.2 \pm 1.4 \mathrm{pS}(\mathrm{SD})$, respectively. When incorporated into bilayers of PC:PE (1:4) the channel opens to two main open states at $24.1 \pm 0.6 \mathrm{pS}(\mathrm{SD})$ and $17.8 \pm 1.5 \mathrm{pS}(\mathrm{SD})$, respectively. The sub-conductance state was detected at $10.4 \pm 0.8 \mathrm{pS}(\mathrm{SD})$. Each trace is derived from more than 1,500 single channel opening events. (B) I/V curve of the sub-conductance state and the two main-conductance states. The channel opens to three distinct conductance states in a voltage-independent manner. The mean standard error for each point is smaller than the size of the symbols. (C) Opening time histograms of $\mathrm{p} 7$ incorporated into PC-rich and PE-rich lipid bilayers. The mean opening times of $\mathrm{p} 7$ incorporated into bilayers containing 4:1 PC:PE and PC:PE (1:4) was $0.095 \pm 0.018 \mathrm{~s}(\mathrm{SD})$ and $1.0 \pm 0.32 \mathrm{~s}(\mathrm{SD})$, respectively. 

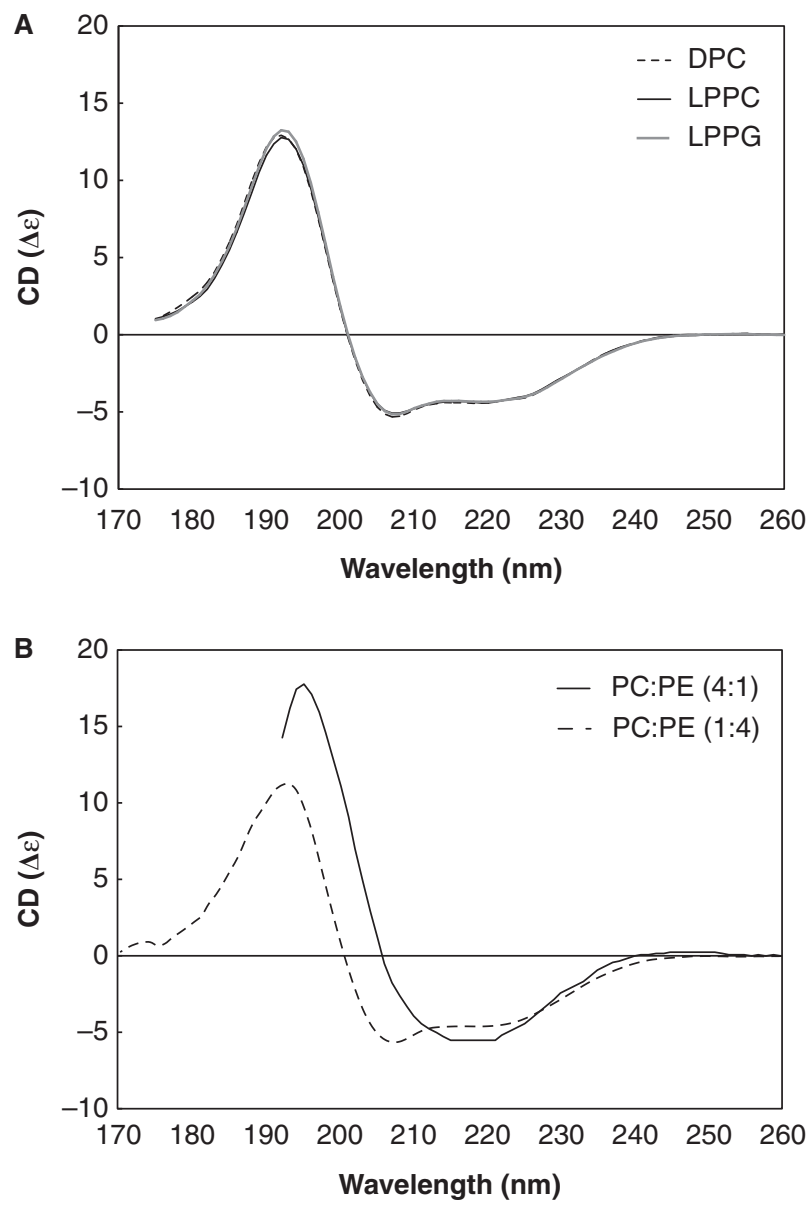

Figure 3. SRCD spectrum of $p 7$ in different lipid environments. (A) SRCD spectra of p7 incorporated in DPC (dotted line), LPPC (thin solid line) and LPPG (thick solid line) detergents. (B) SRCD spectra of $\mathrm{p} 7$ in PC-rich (solid line) and PE-rich (dotted line) SUVs.

database have similar structural characteristics to this peptide. However, the spectrum closely resembled that of another viroporin, the influenza $B$ virus NB protein (Fischer et al. 2000).

\section{Discussion}

HCV p7 is a viroporin, a small, hydrophobic viral membrane protein that modifies the permeability of the cell membrane to ions and other small molecules (Gonzalez and Carrasco 2003). Other viroporins include influenza A virus M2, which facilitates virus entry and exit, and HIV-1 Vpu and 6k of the alphaviruses, which both facilitate virus assembly and release (Neil et al. 2008). The crystal structure of the transmembrane-spanning region of $\mathrm{M} 2$ is the first highresolution structure of a viroporin (Stouffer et al. 2008). In support of the classification of $\mathrm{p} 7$ as a viroporin, we and others have shown that $\mathrm{p} 7$ forms ion channels (Griffin et al. 2003, Pavlovic et al. 2003, Premkumar et al. 2004), and the critical role of $\mathrm{p} 7$ in the assembly and release of infectious virions has been described (Steinmann et al. 2007). The currents reported here are similar in size and selectivity to that reported previously (Premkumar et al. 2004) for $\mathrm{p} 7$ in a mixture of similar lipids POPC, POPS, POPE (2:3:5). That study also demonstrated that calcium ions appear to affect the selectivity of the channel. This effect could be mediated directly by interaction with the $\mathrm{p} 7$ protein itself or indirectly via the calcium ions interacting with the lipids.

Here, the effect of the lipid environment on the HCV p7 ion channel structure was investigated in order to further our understanding of the effect lipids may have on p7 function. Lipid bilayer compositions vary greatly, not just in different cell types but also in the membranes of various subcellular organelles such as the ER, Golgi and plasma membrane (Kolomiytseva et al. 2003). The subcellular lipidome is also heavily influenced by and changes in response to, for example, cell activation (Andreyev et al. 2010). Within the ER membrane, the primary location of $\mathrm{p} 7$, the lipid composition differs between the inner and outer leaflets, and within a given leaflet it is both heterogeneous and highly dynamic (Bollen and Higgins 1980). The lipid composition of these leaflets can affect the structure and function of membrane proteins through specific and non-specific interactions and the effects of membrane composition on ion channel have been reported previously (Keller et al. 1993, Chang et al. 1995a, 1995b, Turnheim et al. 1999, Valiyaveetil et al. 2002, Gallucci et al. 2003, Tillman and Cascio 2003, Schmidt et al. 2006, Weber et al. 2006).

P7 resides predominantly in the ER of infected hepatocytes (Carrere-Kremer et al. 2002, Haqshenas et al. 2007). The major lipid components of the hepatocyte ER are PC and PE; other ER lipids include phosphatidylserine (PS), phosphatidylinositol (PI), sphingomyelin, and cholesterol (Davison and Wills 1974). We explored the effect of the lipid environment on 77 using biophysical techniques. Our studies focused on PC- and PE-rich bilayers; these lipids constitute approximately $51 \%$ and $23 \%$, respectively, of the ER membrane (Bollen and Higgins 1980). Others have reported such lipid composition mediated effects on an ion channel's activity and structure, e.g., the lipid composition has an effect on the activity of $\mathrm{Ca}^{2+}$ ATPase of the sarcoplasmic reticulum (Navarro et al. 1984) and Tillman and Cascio proposed that the responsiveness of $\mathrm{K}+$ ion channels and the ligandgated nicotinic receptors to changes in the lipid environment are regulated via cellular control of membrane composition (Tillman and Cascio 2003). The influence of lipid on potassium channel (Valiyaveetil et al. 2002, Schmidt et al. 2006) and nicotinic acetylcholine receptors (Hamouda et al. 2006) has been well studied (see recent reviews in Lee 2004, 2009, Barrantes et al. 
2010). Several other groups reported the effects of phospholipid headgroups on the activity of ion channels, both synthetic and natural (Chang et al. 1995a, 1995b, Turnheim et al. 1999, Gallucci et al. 2003, Tillman and Cascio 2003, Duclohier 2006, Weber et al. 2006).

The functionality of $\mathrm{p} 7$ is clearly dependent on the composition of the lipid environment. In the artificial black lipid membrane system, p7 displays short, burst-like openings in a PC-rich bilayer, in contrast to the distinct, long lasting opening events observed in PE-rich bilayers. The average opening time of a single channel opening event was approximately 10 times longer in PE-rich bilayers than in PC-rich bilayers (Figure 1A, Figure 2C). A similar observation was made for alamethicin with DOPC or DOPE rich bilayers (Keller et al. 1993). Those authors reported that significantly shorter channel bursts occur in DOPC than in DOPE bilayers.

However, the lipid composition did not affect the channel's typical current amplitude histogram, with two main and one sub-conductance states and similar IV curves observed in each case. A similar observation was reported by (Keller et al. 1993) in their study of the lipid dependence of alamethicin. This pattern suggests that the functional differences observed are due to the lipid dependence of the $\mathrm{p} 7$ ion channel rather than overall different channel functionality. The planar lipid bilayers used for the electrophysiology experiments contained decane as the lipid dissolvent. The properties of decane-containing bilayers differ from those containing other dissolvents, such as squalene or hexadecane which have a much smaller mole fraction of solvent in the bilayer (White 1978), and the possibility has been raised that lipid effects in membranes formed using higher molecular weight solvents may differ significantly from those in membranes formed with decane. We tested a range of different lipid dissolvents including hexadecane (Supplementary Table 3, available online), and found that in the context of the improved peptide incorporation protocol decane achieved the best results with regards to the establishment of consistent single channel openings.

One should also keep in mind that in these experiments, a $100 \mathrm{~Hz}$ was applied when recording the channel traces. Thus, if there is a small population of short-lived transitions, they would not have been detected by our experimental set-up and are not reflected in the open-time histograms shown.

When incorporated into the membranes of PE-rich SUVs, the secondary structure of $\mathrm{p} 7$ is predominantly $\alpha$-helical (Figure 3B, dashed line) as measured by SRCD spectroscopy. When incorporated into PC-rich SUVs, p7 adopts a distinctly different, unusual spectrum, suggesting a significantly different conformational state. The SRCD spectrum shows an intriguing similarity to that of the influenza $B$ virus ion channel NB (Fischer et al. 2000). NB monomers also contain only a single transmembrane segment (Bak et al. 2001). Our data suggest that predominance of PE promotes a channel formation consisting of a standard $\alpha$-helical hairpin conformation whereas an abundance of PC triggers a helical channel conformation which may be more similar to viral ion channels whose $\mathrm{N}$ - and $\mathrm{C}$-termini are located on opposite sides of the membrane.

Both a double membrane-spanning hairpin topology with the N- and C-termini facing the ER lumen (Carrere-Kremer et al. 2002) as well as an L-shaped form of $\mathrm{p} 7$ have been reported previously (Griffin et al. 2005). The L-shaped form, with the C-terminus facing the cytoplasm, was proposed to be an inactive transport form of $\mathrm{p} 7$ that may regulate localization and oligomerization of the ion channel. The similarity of the p7 SRCD spectrum in PC rich bilayers to the spectra of NB could indicate the presence of a single transmembrane segment. One could then speculate that in a living cell environment a dynamic equilibrium between the L-shaped and hairpin structures might exist depending on the predominant lipids encountered. PC is the predominant lipid of ER membranes. In a PC rich environment we observe short, burst-like openings in BLM experiments. We recently proposed a model for the p7 ion channel based on single particle electron microscopy (Luik et al. 2009) whereby hairpin monomers formed a pore. However, this does not by any means exclude the possibility of a pore formed by L-shaped monomers or a combination of both forms. What is clear at this stage is that the precise conformation of the pore is likely to be dynamic and lipid-dependent. Intercalating $\mathrm{PC}$ and PE headgroups might modulate $\mathrm{p} 7$ monomer topology and potentially the channel oligomerization state by their varying capacity for hydrogen bond formation, as has been proposed for dermaseptins, whose activity is also influenced by the bilayer lipid composition (Duclohier 2006). A recent study on the mechanosensitive channel (MscL) from S. aureus demonstrated a clear dependence of the oligomerization state upon the nature of the detergent used (Dorwart et al. 2010). Thus, there is a clear precedent for the influence of the lipid environment on the behaviour of the channel structure.

If, in PC-rich bilayers, $\mathrm{p} 7$ monomers were to adopt an L-shaped topology, the resulting channels would be lined by either 6 or possibly 7 TM helices. A channel formed by hairpin monomers in a PErich bilayer would feature 12 or $14 \mathrm{TM}$ helices, respectively, with the inner TM helices being supported by the peripheral helices. Unlike the case of HIV Vpu, where the $\mathrm{N}$-terminal transmembrane 
segment alone can form functional ion channels (and in which case the C-terminal amphipathic helix lies parallel to the membrane surface resulting in an overall L-shaped topology), the $\mathrm{p} 7 \mathrm{~N}$-terminal transmembrane segment alone is not capable of forming ion channels (Pavlovic et al. 2003), and the presence of the C-terminal region is important for channel activity. P7 may have different functions depending on whether it occurs in the form of uncleaved E2p7NS2 and E2p7, or free p7. The cellular membrane environment might induce topological changes in $\mathrm{p} 7$ monomers which may influence the channel oligomerization pattern and/or regulate assembled ion channel behaviour in other ways.

\section{Conclusion}

The effects of lipid composition on the function and structure of the HCV p7 ion channel have been demonstrated. There are distinct differences seen in both channel properties and secondary structure of the peptide in lipid bilayers that are rich in PC and $\mathrm{PE}$ headgroups. We suggest that HCV exploits conformational changes of 77 monomers as well as of assembled channels to regulate the channel function at various stages during the viral replication cycle.

\section{Acknowledgements}

Access to the UV1 beamline is acknowledged under the EU Integrated Infrastructure Initiative (I3), Integrated Activity on Synchrotron and Free Electron Laser Science (IA-SFS), contract number RII3-CT-2004-506008. NZ is a Senior Research Fellow of Linacre College, Oxford, and a Glycobiology Career Development Fellow. CC thanks the Wellcome Trust and the Overseas Research Students Awards Scheme. PCB is an RCUK Fellow and thanks the Wellcome Trust for support.

Declaration of interest: This work was supported by the Oxford Glycobiology Institute Endowment, the Cusanuswerk and project grants (D008581 and H023852) from the Biotechnology and Biological Research Council (to BAW). The SRCD work at the ISA synchotron (Denmark) was supported by beamtime grants to TW and BAW. The authors report no conflicts of interest. The authors alone are responsible for the content and writing of the paper.

\section{References}

Andreyev AY, Fahy E, Guan Z, Kelly S, Li X, McDonald JG, Milne S, Myers D, Park H, Ryan A, Thompson BM, Wang E, Zhao Y, Brown HA, Merrill AH, Raetz CRH, Russell DW,
Subramaniam S, Dennis EA. 2010. Subcellular organelle lipidomics in TLR-4-activated macrophages. J Lipid Res 51:27852797.

Bak M, Bywater RP, Hohwy M, Thomsen JK, Adelhorst K, Jakobsen HJ, Sørensen OW, Nielsen NC. 2001. Conformation of alamethicin in oriented phospholipid bilayers determined by $15 \mathrm{~N}$ solid-state nuclear magnetic resonance. Biophys J 81:1684-1698.

Barrantes F, Bermudez V, Borroni M, Antollini S, Pediconi M, Baier J, Bonini I, Gallegos C, Roccamo A, Valles A, Ayala V, Kamerbeek C. 2010. Boundary lipids in the nicotinic acetylcholine receptor microenvironment. J Mol Neurosci 40: 87-90.

Bollen IC, Higgins JA. 1980. Phospholipid asymmetry in roughand smooth-endoplasmic-reticulum membranes of untreated and phenobarbital-treated rat liver. Biochem J 189:475-480.

Carrere-Kremer S, Montpellier-Pala C, Cocquerel L, Wychowski C, Penin F, Dubuisson J. 2002. Subcellular localization and topology of the p7 polypeptide of hepatitis C virus. J Virol 76:3720-3730.

Chang HM, Reitstetter R, Gruener R. 1995a. Lipid-ion channel interactions: increasing phospholipid headgroup size but not ordering acyl chains alters reconstituted channel behavior. J Membr Biol 145:13-19.

Chang HM, Reitstetter R, Mason RP, Gruener R. 1995b. Attenuation of channel kinetics and conductance by cholesterol: An interpretation using structural stress as a unifying concept. J Membr Biol 143:51-63.

Chew CF, Vijayan R, Chang J, Zitzmann N, Biggin PC. 2009. Determination of pore-lining residues in the hepatitis $\mathrm{C}$ virus p7 protein. Biophys J 96:L10-L12.

Clarke D, Griffin S, Beales L, Stgelais C, Burgess S, Harris M, Rowlands D. 2006. Evidence for the formation of a heptameric ION channel complex by the hepatitis $\mathrm{C}$ virus $\mathrm{P} 7$ protein in vitro. J Biol Chem 281:37057-37068.

Cook G, Opella S. 2010. NMR studies of $\mathrm{p} 7$ protein from hepatitis C virus. Eur Biophys J 39:1097-1104.

Davison SC, Wills ED. 1974. Studies on the lipid composition of the rat liver endoplasmic reticulum after induction with phenobarbitone and 20-methylcholanthrene. Biochem J 140: 461-468.

Di Bisceglie AM. 1997. Hepatitis C and hepatocellular carcinoma. Hepatology 26:34S-38S.

Dorwart MR, Wray R, Brautigam CA, Jiang Y, Blount P. 2010. S. aureus $\mathrm{MscL}$ is a pentamer in vivo but of variable stoichiometries in vitro: Implications for detergent-solubilized membrane proteins. PLoS Biol 8:e1000555.

Duclohier H. 2006. Bilayer lipid composition modulates the activity of dermaseptins, polycationic antimicrobial peptides. Eur Biophys J 35:401-409.

Feld JJ, Hoofnagle JH. 2005. Mechanism of action of interferon and ribavirin in treatment of hepatitis C. Nature 436:967-972.

Fischer WB, Pitkeathly M, Wallace BA, Forrest LR, Smith GR, Sansom MS. 2000. Transmembrane peptide NB of influenza B: A simulation, structure, and conductance study. Biochemistry 39:12708-12716.

Gallucci E, Meleleo D, Micelli S, Picciarelli V. 2003. Magainin 2 channel formation in planar lipid membranes: The role of lipid polar groups and ergosterol. Eur Biophys J 32:22-32.

Gonzalez ME, Carrasco L. 2003. Viroporins. FEBS Lett 552: 28-34.

Griffin S, Clarke D, McCormick C, Rowlands D, Harris M. 2005. Signal peptide cleavage and internal targeting signals direct the hepatitis $\mathrm{C}$ virus $\mathrm{p} 7$ protein to distinct intracellular membranes. J Virol 79:15525-15536. 
Griffin SD, Beales LP, Clarke DS, Worsfold O, Evans SD, Jaeger J, Harris MP, Rowlands DJ. 2003. The p7 protein of hepatitis C virus forms an ion channel that is blocked by the antiviral drug, Amantadine. FEBS Lett 535:34-38.

Griffin SD, Harvey R, Clarke DS, Barclay WS, Harris M, Rowlands DJ. 2004. A conserved basic loop in hepatitis C virus p7 protein is required for amantadine-sensitive ion channel activity in mammalian cells but is dispensable for localization to mitochondria. J Gen Virol 85:451-461.

Hamouda AK, Sanghvi M, Sauls D, Machu TK, Blanton MP. 2006. Assessing the lipid requirements of the Torpedo californica nicotinic acetylcholine receptor. Biochemistry 45: 4327-4337.

Haqshenas G, Mackenzie JM, Dong X, Gowans EJ. 2007. Hepatitis $\mathrm{C}$ virus $\mathrm{p} 7$ protein is localized in the endoplasmic reticulum when it is encoded by a replication-competent genome. J Gen Virol 88:134-142.

Ismailov II, Berdiev BK, Benos DJ. 1995. Regulation by $\mathrm{Na}+$ and $\mathrm{Ca} 2+$ of renal epithelial $\mathrm{Na}+$ channels reconstituted into planar lipid bilayers. J Gen Physiol 106:445-466.

Keller SL, Bezrukov SM, Gruner SM, Tate MW, Vodyanoy I, Parsegian VA. 1993. Probability of alamethicin conductance states varies with nonlamellar tendency of bilayer phospholipids. Biophys J 65:23-27.

Kolomiytseva IK, Perepelkina NI, Patrushev IV, Popov VI. 2003. Role of lipids in the assembly of endoplasmic reticulum and dictyosomes in neuronal cells from the cerebral cortex of Yakutian ground squirrel (Citellus undulatus) during hibernation. Biochemistry (Mosc) 68:783-794.

Lee A. 2009. The effects of lipids on channel function. J Biol 8:86.

Lee AG. 2004. How lipids affect the activities of integral membrane proteins. Biochim Biophys Acta (Biomembranes) 1666: $62-87$.

Lees JG, Smith BR, Wien F, Miles AJ, Wallace BA. 2004. CDtoolan integrated software package for circular dichroism spectroscopic data processing, analysis, and archiving. Anal Biochem 332:285-289.

Lin C, Lindenbach BD, Pragai BM, McCourt DW, Rice CM. 1994. Processing in the hepatitis C virus E2-NS2 region: Identification of $\mathrm{p} 7$ and two distinct E2-specific products with different C termini. J Virol 68:5063-5073.

Luik P, Chew C, Aittoniemi J, Chang J, Wentworth P, Dwek RA, Biggin PC, Venien-Bryan C, Zitzmann N. 2009. The 3-dimensional structure of a hepatitis $\mathrm{C}$ virus $\mathrm{p} 7$ ion channel by electron microscopy. Proc Natl Acad Sci USA 106:12712-12716.

Mehnert T, Routh A, Judge PJ, Lam YH, Fischer D, Watts A, Fischer WB. 2007. Biophysical characterization of Vpu from HIV-1 suggests a channel-pore dualism. Proteins: Struct, Func, Gen 70:1488-1497.

Melton JV, Ewart G, Weir RC, Board PG, Lee E, Gage PW. 2002. Alphavirus $6 \mathrm{~K}$ proteins form ion channels. J Biol Chem 277:46923-46931.

Miles AJ, Wallace BA. 2006. Synchrotron radiation circular dichroism spectroscopy of proteins and applications in structural and functional genomics. Chem Soc Rev 35:39-51.

Myers VB, Haydon DA. 1972. Ion transfer across lipid membranes in the presence of gramicidin A. II. The ion selectivity. Biochim Biophys Acta 274:313-322.

Navarro J, Toivio-Kinnucan M, Racker E. 1984. Effect of lipid composition on the calcium/adenosine $5^{\prime}$-triphosphate coupling ratio of the $\mathrm{Ca} 2+-\mathrm{ATPase}$ of sarcoplasmic reticulum. Biochemistry $23: 130-135$.

Neil SJ, Zang T, Bieniasz PD. 2008. Tetherin inhibits retrovirus release and is antagonized by HIV-1 Vpu. Nature 451: 425-430.
Patargias G, Zitzmann N, Dwek R, Fischer WB. 2006. Proteinprotein interactions: Modeling the hepatitis $\mathrm{C}$ virus ion channel p7. J Med Chem 49:648-655.

Pavlovic D, Neville DC, Argaud O, Blumberg B, Dwek RA, Fischer WB, Zitzmann N. 2003. The hepatitis C virus p7 protein forms an ion channel that is inhibited by longalkyl-chain iminosugar derivatives. Proc Natl Acad Sci USA 100:6104-6108.

Premkumar A, Wilson L, Ewart GD, Gage PW. 2004. Cationselective ion channels formed by $\mathrm{p} 7$ of hepatitis $\mathrm{C}$ virus are blocked by hexamethylene amiloride. FEBS Lett 557:99-103.

Sakai A, Claire MS, Faulk K, Govindarajan S, Emerson SU, Purcell RH, Bukh J. 2003. The p7 polypeptide of hepatitis C virus is critical for infectivity and contains functionally important genotype-specific sequences. Proc Natl Acad Sci USA 100:11646-11651.

Savitsky A, Golay M. 1964. Smoothing and differentiation of data by simplified least squares procedures. Anal Chem 36:1627-1639.

Schmidt D, Jiang Q-X, MacKinnon R. 2006. Phospholipids and the origin of cationic gating charges in voltage sensors. Nature 444:775-779.

Schnolzer M, Alewood P, Jones A, Alewood D, Kent SB. 1992. In situ neutralization in Boc-chemistry solid phase peptide synthesis. Rapid, high yield assembly of difficult sequences. Int J Pept Protein Res 40:180-193.

Sreerama N, Venyaminov SY, Woody RW. 1999. Estimation of the number of alpha-helical and beta-strand segments in proteins using circular dichroism spectroscopy. Protein Sci 8: 370-380.

Sreerama N, Woody RW. 1993. A self-consistent method for the analysis of protein secondary structure from circular dichroism. Anal Biochem 209:32-44.

Sreerama N, Woody RW. 2000. Estimation of protein secondary structure from circular dichroism spectra: Comparison of CONTIN, SELCON, and CDSSTR methods with an expanded reference set. Anal Biochem 287:252-260.

Steinmann E, Penin F, Kallis S, Patel AH, Bartenschlager R, Pietschmann T. 2007. Hepatitis C virus p7 protein is crucial for assembly and release of infectious virions. PLoS Pathog 3:e103.

Stouffer AL, Acharya R, Salom D, Levine AS, Di Costanzo L, Soto CS, Tereshko V, Nanda V, Stayrook S, DeGrado WF. 2008. Structural basis for the function and inhibition of an influenza virus proton channel. Nature 451:596-599.

Tillman TS, Cascio M. 2003. Effects of membrane lipids on ion channel structure and function. Cell Biochem Biophys 38:161-190.

Turnheim K, Gruber J, Wachter C, Ruiz-Gutierrez V. 1999. Membrane phospholipid composition affects function of potassium channels from rabbit colon epithelium. Am J Physiol 277:C83C90.

Valiyaveetil FI, Zhou Y, MacKinnon R. 2002. Lipids in the structure, folding, and function of the KcsA K+ channel. Biochemistry 41:10771-10777.

van Stokkum IH, Spoelder HJ, Bloemendal M, van Grondelle R, Groen FC. 1990. Estimation of protein secondary structure and error analysis from circular dichroism spectra. Anal Biochem 191:110-118.

Wallace BA, Mao D. 1984. Circular dichroism analyses of membrane proteins: An examination of differential light scattering and absorption flattening effects in large membrane vesicles and membrane sheets. Anal Biochem 142:317-328.

Weber ME, Elliott EK, Gokel GW. 2006. Activity of synthetic ion channels is influenced by cation-pi interactions with phospholipid headgroups. Org Biomol Chem 4:83-89. 
White SH. 1978. Formation of 'solvent-free' black lipid bilayer membranes from glyceryl monooleate dispersed in squalene. Biophys J 23:337-347.

Whitmore L, Wallace BA. 2008. Protein secondary structure analyses from circular dichroism spectroscopy: Methods and reference databases. Biopolymers 89:392-400.
Wozniak AL, Griffin S, Rowlands D, Harris M, Yi M, Lemon SM, Weinman SA. 2010. Intracellular proton conductance of the hepatitis $\mathrm{C}$ virus $\mathrm{p} 7$ protein and its contribution to infectious virus production. PLoS Pathog 6:e1001087.

Yang Y, Yan Y, Sigworth FJ. 1997. How does the W434F mutation block current in Shaker potassium channels? J Gen Physiol 109:779-789.

\section{Supplementary material available online}

Supplementary Tables 1-3. 